\title{
Following Lung Resection: Does the volume of perioperative fluid affect patient outcomes?
}

\author{
Megumi Asai, Andres X Samayoa, Caitlin Hodge, Ho Pak, \\ Orlando C Kirton and Thai Vu \\ Department of Surgery, Abington Hospital - Jefferson Health, Department of Surgery, Price Medical Office Bldg. 1245 Highland Ave. Ste 600, \\ Abington, PA 19001, USA
}

Received: 22 August, 2017; Accepted: 18 November, 2017; Published: June 06, 2018

*Corresponding author: Vu Thai, Associate Surgeon, Department of Surgery, Abington Hospital Jefferson Health Price Medical Office Bldg. 1245 Highland Ave. Ste 600, Abington, PA 19001, USA, Tel: 215-887-3990; Fax: 215-887-1140; Email: thai.vu@jefferson.edu

\begin{abstract}
Introduction: Appropriate amount of intraoperative intravenous (IV) fluid has been controversial in thoracic surgery. In our study, we investigated outcome measures associated with patients undergoing lung resection for non-small cell lung cancer (NSCLC) and the correlation with perioperative IV fluids.

Methods: A retrospective review of consecutive patients undergoing open lobectomy and bilobectomy for primary NSCLC between January 2010 and June 2016 was performed. Patient were divided into those receiving intraoperative IV fluid less than $7 \mathrm{cc} /$ $\mathrm{kg} / \mathrm{hr}, 7$ to $10 \mathrm{cc} / \mathrm{kg} / \mathrm{hr}$, and equal to or greater than $10 \mathrm{cc} / \mathrm{kg} / \mathrm{hr}$. Postoperative IV fluid was also recorded. We compared this against patient's demographics, intraoperative parameters and complication rate.
\end{abstract}

Results: 142 patients with the mean age of 66.5 years were identified. There was no significant difference in the hospital or ICU stay between any of the groups. Patients who received greater than $10 \mathrm{cc} / \mathrm{kg} / \mathrm{hr}$ intraoperative IV fluids have higher rate of one or more complications and reoperation rate. Patients who had greater than $1.5 \mathrm{cc} / \mathrm{kg} / \mathrm{hr}$ perioperative fluid have significantly higher duration of chest tube in-situ and pulmonary complication rate. Patients receiving less than $7 \mathrm{cc} / \mathrm{kg} / \mathrm{hr}$ intraoperative IV fluids have no benefits compare to the group receiving larger IV fluid.

Conclusions: In our study, giving high amounts of intraoperative and perioperative IV fluid has adverse effects on postoperative complications. Giving less $(<7 \mathrm{cc} / \mathrm{kg} / \mathrm{hr})$ intraoperative IV fluid has no additional benefits. We propose the optimal amount of intraoperative and perioperative IV fluid given should be in between these two extremes.

Keywords: Lung resection; Non-small cell lung cancer Outcomes; Perioperative fluids

\section{Introduction}

Lung resection has been the mainstay of the treatment for early stage non-small cell lung cancer (NSCLC), with lobectomy being the most commonly performed procedure [1]. Although tremendous efforts have been made to improve outcomes and mortality, morbidity after lung resections remains high [1-3]. Perioperative risk factors related to postoperative complications, especially pulmonary complications, have been discussed in previous studies, but methods for reducing complications still remains controversial. A major piece of this debate surrounds intravenous (IV) fluid management. A few case-control studies have shown an association between perioperative fluids and complications of respiratory outcomes. However, there is limited data available to assess the effects of restricting perioperative fluids on overall outcomes.

In this study, we investigated outcome measures associated with patients undergoing lung resection for NSCLC and the correlation with volume of perioperative IV fluids.

\section{Materials and Methods}

\section{Design}

All patients who underwent elective open lobectomy and bilobectomy for primary NSCLC at our institution between January 2010 and June 2016 were identified using our cancer center database and retrospectively reviewed. Exclusion criteria included previous lung resection(s) on the ipsilateral side of the operation. Patients who had intraoperative blood loss more than $500 \mathrm{cc}$ or who required intraoperative blood transfusions during surgery were also excluded, as excess blood loss during surgery independently leads to worse outcomes.

Preoperative evaluation included a complete history and physical examination, full blood count, biochemical profile and computed tomographic (CT) scan of chest. Pulmonary function test was also performed for majority of the patients. Patient who had a history of or major risk for cardiovascular disease underwent cardiologic evaluation. Relevant comorbidities, tobacco, and alcohol abuse were identified. Alcohol abuse was defined by consumption of hard liquor more than 2 ounces, or beer more than two of $12 \mathrm{oz}$. cans, or wine more than two $6 \mathrm{oz}$. glasses per day more than 5 times a week.

All patients had a radial arterial catheter for hemodynamic management and ureteral catheter for accurate urine output measurement perioperatively. Preoperative antibiotics and chemical deep venous thrombosis (DVT) prophylaxis were given. Patients were intubated with a double-lumen endotracheal tube and the operative lung was deflated during the surgery to facilitate dissection. Lung resections were performed with systemic lymph node dissection through a full posterolateral or lateral muscle- 
sparing thoracotomy. Patients were extubated in the operating room or in the recovery area immediately after the transfer if there was no respiratory concern. All patients were monitored in the surgical intensive care unit (ICU) post operatively for at least 24 hours.

The primary exposure investigated in this study was volume of intraoperative and perioperative IV fluids, in $\mathrm{cc} / \mathrm{kg} / \mathrm{hr}$ Intraoperative IV fluids were defined as only those fluids given in the operating room. Perioperative IV fluids were defined as intraoperative IV fluids and postoperative IV fluid within 24 hours from surgery. This did not include oral fluid intake. For intraoperative fluids, patients were divided into three groups; restrictive (those receiving intraoperative IV fluid less than 7 $\mathrm{cc} / \mathrm{kg} / \mathrm{hr}$ ), typical (those receiving 7 to $10 \mathrm{cc} / \mathrm{kg} / \mathrm{hr}$ ), and liberal (those receiving equal to or greater than $10 \mathrm{cc} / \mathrm{kg} / \mathrm{hr}$ ). For perioperative fluids, patients were categorized into high fluids group (those receiving greater than $1.5 \mathrm{cc} / \mathrm{kg} / \mathrm{hr}$ ) or low fluids group (less than $1.5 \mathrm{cc} / \mathrm{kg} / \mathrm{hr}$ ).

The primary outcomes investigated in this study were duration of hospital and ICU stay, length of chest tube in situ, and complications within 30 days of surgery. Complications were categorized as pulmonary, cardiovascular, and renal in etiology. Major hemorrhage, death and reoperation rate were also received. Pulmonary complications were classified as acute lung injury (ALI), acute respiratory distress syndrome (ARDS), prolonged intubation or re-intubation, pneumonia, empyema and bronchopleural fistula. ALI and ARDS were defined by the criteria established at The American-European Consensus Conference: 1) sudden onset of respiratory distress; 2) diffuse pulmonary infiltrates on chest radiograph consistent with alveolar edema; 3) $\mathrm{PaO2} / \mathrm{FIO} 2$ ratio of $<300$ for ALI and < 200 for ARDS; and 4) absence of hydrostatic pulmonary edema on the basis of pulmonary arterial catheterization, echocardiogram, laboratory data and clinical evaluation [4]. Other pulmonary conditions such as atelectasis, effusions and chylothorax were included only if the patient required medical, bronchoscopic, interventional radiology or surgical intervention. Cardiovascular complications included deep venous thrombosis (DVT), pulmonary embolus (PE), any arrhythmias that require acute treatment, and new onset or worsening of heart failure diagnosed on echocardiogram or intravascular monitoring. Renal complication was defined as acute kidney injury (AKI) with absolute increase in serum creatinine of more than or equal to $0.3 \mathrm{mg} / \mathrm{dL}$ or more than or equal to 50 $\%$ from the base line creatinine, or a reduction in urine output less than $0.5 \mathrm{cc} / \mathrm{kg}$ per hour for more than 6 hours. Patient who required blood transfusions for acute decrease in hemoglobin, reoperation for or radiologic finding of demonstrated bleeds were classified as having major hemorrhage.

This study was exempt from Institutional Review Board approval under category 45 CFR 46.101 (b) (4).

\section{Statistical analysis}

Chi-square, One-way ANOVA and t-tests were used for statistical analysis. All tests were two tailed. The tolerance for a type I error was 0.05. Missing data were excluded from the calculation of proportions unless otherwise specified. The data analysis was performed using the IBM SPSS v. 24 (IBM Corp., Armonk, NY).

\section{Results \\ Clinical characteristics of patient populations}

A total of 151 patients underwent elective lobectomy or bilobectomy for primary NSCLC during the study period and comprised the study group. Of those, 5 patients were excluded from this study due to intraoperative blood loss more than 500 cc and/or transfusion, and 4 patients were excluded for previous lung resection. Of 142 patients who met inclusion criteria, 131 patients $(92.3 \%)$ underwent lobectomy and 11 patients $(7.7 \%)$ underwent bilobectomy. The average age was 66.5 (range 27-86) and $73(51.4 \%)$ were female. 19 patients $(13.3 \%)$ had advanced stage (stage III and VI) cancer and 17 patients (12.0\%) received neoadjuvant chemoradiation therapy. The mean operation time was 236 minutes with blood loss of 153 cc. Two patients were kept intubated and extubated within 24 hour postoperatively in the ICU. The remining 140 patients were extubated in the operating room or in the recovery area immediately after the transfer.

The mean hospital and ICU stay were 8.1 and 4.2 days respectively. The chest tube was removed after 5.6 days on average. 45 patients $(31.7 \%)$ had one or more complications. Pulmonary complications were the most common, occurring in 27 patients (19\%) followed by cardiovascular complications in 17 patients $(12.0 \%)$. Hemorrhage and renal injury occurred in 11 patients $(7.7 \%)$ and 6 patients $(4.2 \%)$ respectively. Mortality was $3.5 \%$. The power of this study was 0.90 .

\section{Intraoperative IV fluids}

68 patients (47.9\%) were in the restrictive group, 47 patients (33.1\%) were in the typical group, and 27 patients $(19.0 \%)$ were in the liberal group (Table 1). There was no difference in age, comorbidities, stage of cancer, or rate of neoadjuvant chemoradiation therapy in three groups. Intraoperative blood loss and peak pressure during surgery were not significantly different between the groups. Female patients were more common in the typical and liberal groups $(\mathrm{p}=0.028)$. Larger BMI and longer operation time were associated with smaller amount of perioperative fluid ( $\mathrm{p}=0.000$ and 0.001 respectively). Tidal volume per ideal body weight were larger in the groups receiving more fluid $(\mathrm{p}=0.046)$.

Outcomes related to intraoperative IV fluid are shown in Table 2. There was no difference in duration of hospital stay, ICU stay, and chest tube in situ. Patients with one or more complications were observed more frequently in the group receiving liberal intraoperative IV fluid $(51.9 \%, \mathrm{p}=0.043)$. The rate of re-operation was also significantly higher in this group $(11.1 \%, \mathrm{p}=0.014)$. All six patients with acute renal injury occurred in the restrictive group $(8.8 \%, p=0.033)$. No statistically significant difference was seen in the occurrence of other complications.

\section{Perioperative IV fluids}

40 patients $(28.2 \%)$ were in the low fluids group and 102 patients $(71.8 \%)$ were in the high fluids group (Table 3 ). There was no difference in age, gender, or rate of neoadjuvant chemoradiation therapy in two groups. The group receiving less perioperative IV fluid had higher BMI $(p=0.001)$. The group 
Following Lung Resection: Does the volume of perioperative fluid affect patient outcomes?

Table 1: Demographics, risk factors, details of operative procedures with different amount of intraoperative fluid

\begin{tabular}{|c|c|c|c|c|}
\hline & $\begin{array}{c}\text { Intraoperative fluid } \\
<7 \mathrm{cc} / \mathrm{kg} / \mathrm{hr} \\
(n=68)\end{array}$ & $\begin{array}{l}\text { Intraoperative fluid } \\
7-10 \mathrm{cc} / \mathrm{kg} / \mathrm{hr}(\mathrm{n}=47)\end{array}$ & $\begin{array}{c}\text { Intraoperative fluid } \\
\geq 10 \mathrm{cc} / \mathrm{kg} / \mathrm{hr} \\
(n=27)\end{array}$ & P-value \\
\hline Age, mean [years] & 67.5 & 67.0 & 63.2 & 0.131 \\
\hline Gender, female, n (\%) & 27 (39.7) & $29(61.7)$ & $17(63.0)$ & $0.028^{*}$ \\
\hline BMI, mean & 29.9 & 27.2 & 23.7 & $0.000^{*}$ \\
\hline ASA class > 2, n (\%) & $51(75.0)$ & 37 (78.7) & $20(74.1)$ & 0.868 \\
\hline Diabetes, n (\%) & $14(20.6)$ & $9(19.1)$ & $2(7.4)$ & 0.297 \\
\hline Coronary artery disease, $\mathrm{n}(\%)$ & $14(20.6)$ & $9(19.1)$ & $3(11.1)$ & 0.551 \\
\hline Peripheral vascular disease, n (\%) & $5(7.4)$ & $3(6.4)$ & $2(7.4)$ & 0.977 \\
\hline $\begin{array}{l}\text { Chronic obstructive pulmonary } \\
\text { disease , n (\%) }\end{array}$ & $39(57.4)$ & $19(40.4)$ & $15(55.6)$ & 0.181 \\
\hline Chronic kidney disease , n (\%) & $17(25.0)$ & $8(17.0)$ & 7 (25.9) & 0.540 \\
\hline Chronic alcohol use, n (\%) & $5(7.4)$ & $6(12.8)$ & $2(7.4)$ & 0.577 \\
\hline FEV , mean [\% predicted value] & 80.4 & 87.3 & 82.4 & 0.141 \\
\hline $\begin{array}{c}\text { Advanced TMN stages (III-IV), } \mathrm{n} \\
(\%)\end{array}$ & $5(7.4)$ & 7 (14.9) & $7(25.9)$ & 0.053 \\
\hline $\begin{array}{c}\text { Neoadjuvant chemoradiation } \\
\text { therapy, } \mathrm{n}(\%)\end{array}$ & $9(13.2)$ & $3(6.4)$ & $5(18.5)$ & 0.273 \\
\hline Duration of surgery, mean [min] & 257.7 & 232.6 & 187.2 & $0.001 *$ \\
\hline Estimated blood loss, mean [cc] & 169.6 & 136.5 & 140.0 & 0.188 \\
\hline $\begin{array}{l}\text { Tidal volume per ideal body weight } \\
\text { [cc] }\end{array}$ & 7.9 & 8.2 & 8.7 & $0.046^{*}$ \\
\hline Peak inspiratory pressure $\left[\mathrm{cm} \mathrm{H}_{2}\right.$ ] & 25.9 & 25.2 & 24.6 & 0.483 \\
\hline
\end{tabular}

Table 2: Outcome of lung resection with different amount of intraoperative fluid

\begin{tabular}{|c|c|c|c|c|}
\hline & $\begin{array}{c}\text { Intraoperative fluid } \\
<7 \mathrm{cc} / \mathrm{kg} / \mathrm{hr} \\
(n=68)\end{array}$ & $\begin{array}{c}\text { Intraoperative fluid } \\
\begin{array}{c}7-10 \mathrm{cc} / \mathrm{kg} / \mathrm{hr} \\
(n=47)\end{array}\end{array}$ & $\begin{array}{c}\text { Intraoperative fluid } \\
\geq 10 \mathrm{cc} / \mathrm{kg} / \mathrm{hr} \\
(n=27)\end{array}$ & p-value \\
\hline Duration of hospital stay, mean [days] & 8.0 & 8.0 & 8.8 & 0.913 \\
\hline Duration of ICU stay, mean [days] & 4.4 & 4.2 & 3.9 & 0.950 \\
\hline $\begin{array}{l}\text { Duration of chest tube in situ, mean } \\
\text { [days] }\end{array}$ & 4.9 & 6.0 & 7.0 & 0.056 \\
\hline $\begin{array}{l}\text { Patients with one or more complications, } \\
\mathrm{n}(\%)\end{array}$ & $18(26.5)$ & $13(27.7)$ & $14(51.9)$ & $0.043^{*}$ \\
\hline Pulmonary complications, $\mathrm{n}(\%)$ & $12(17.6)$ & $7(14.9)$ & $8(29.6)$ & 0.276 \\
\hline Cardiovascular complications, n (\%) & $7(10.3)$ & $6(12.8)$ & $4(14.8)$ & 0.812 \\
\hline Renal complications, n (\%) & $6(8.8)$ & $0(0.0)$ & $0(0.0)$ & $0.033^{*}$ \\
\hline Hemorrhage, n (\%) & $4(5.9)$ & $2(4.3)$ & $5(18.5)$ & 0.063 \\
\hline Neurologic complications, $\mathrm{n}(\%)$ & $0(0)$ & $1(2.1)$ & $1(3.7)$ & 0.338 \\
\hline Reoperation, n (\%) & $1(1.5)$ & $0(0.0)$ & $3(11.1)$ & $0.014^{*}$ \\
\hline Death, n (\%) & $3(4.4)$ & $0(0.0)$ & $2(7.4)$ & 0.215 \\
\hline
\end{tabular}

receiving more perioperative fluid included more patients with chronic kidney disease (CKD) and advanced stage cancer patients ( $\mathrm{p}=0.043$ and 0.014 respectively). Intraoperative variables and the rate of comorbidities other than CKD and intraoperative variables were similar in both groups.

Outcomes related to perioperative IV fluid are shown in Table 4. There was no difference in duration of hospital and ICU stay. Duration of chest tube in situ was longer in the high fluids group 
Table 3: Demographics, risk factors, details of operative procedures with perioperative fluid greater or less than $1.5 \mathrm{cc} / \mathrm{kg} / \mathrm{hr}$

\begin{tabular}{|c|c|c|c|}
\hline & $\begin{array}{c}\text { Intraoperative fluid < } 1.5 \mathrm{cc} / \\
\mathrm{kg} / \mathrm{hr}(n=40)\end{array}$ & $\begin{array}{l}\text { Intraoperative fluid } \geq 1.5 \mathrm{cc} / \mathrm{kg} / \\
\qquad \operatorname{hr}(n=102)\end{array}$ & p-value \\
\hline Age, mean [years] & 66.6 & 66.5 & 0.967 \\
\hline Male, n (\%) & $22(55.0)$ & $47(46.1)$ & \multirow{2}{*}{0.357} \\
\hline Female, n (\%) & $18(45.0)$ & $55(53.9)$ & \\
\hline BMI, mean & 30.4 & 26.9 & $0.001^{*}$ \\
\hline ASA class $>2, \mathrm{n}(\%)$ & $33(82.5)$ & $75(73.5)$ & 0.285 \\
\hline Diabetes, n (\%) & $10(25.0)$ & $15(14.7)$ & 0.152 \\
\hline Coronary artery disease, $\mathrm{n}(\%)$ & $10(25.0)$ & $16(15.7)$ & 0.230 \\
\hline Peripheral vascular disease, $\mathrm{n}(\%)$ & $1(2.5)$ & $9(8.8)$ & 0.283 \\
\hline $\begin{array}{c}\text { Chronic obstructive pulmonary } \\
\text { disease, } \mathrm{n}(\%)\end{array}$ & $19(47.5)$ & $54(52.9)$ & 0.581 \\
\hline Chronic kidney disease, n (\%) & $14(35.0)$ & $18(17.6)$ & $0.043^{*}$ \\
\hline Chronic alcohol use, n (\%) & $2(5.0)$ & $11(10.8)$ & 0.352 \\
\hline FEV , mean [\% predicted value] & 80.9 & 83.9 & 0.415 \\
\hline $\begin{array}{c}\text { Advanced TMN stages (III-IV), } \mathrm{n} \\
(\%)\end{array}$ & $1(2.5)$ & $18(17.6)$ & $0.014^{*}$ \\
\hline $\begin{array}{c}\text { Neoadjuvant chemoradiation } \\
\text { therapy, } \mathrm{n}(\%)\end{array}$ & $2(5.0)$ & 15 (14.7) & 0.152 \\
\hline Duration of surgery, mean [min] & 243.8 & 232.9 & 0.477 \\
\hline Estimated blood loss, mean [cc] & 152.5 & 153.2 & 0.972 \\
\hline $\begin{array}{l}\text { Tidal volume per ideal body weight } \\
\qquad[\mathrm{cc}]\end{array}$ & 8.3 & 8.2 & 0.997 \\
\hline Peak inspiratory pressure $[\mathrm{cm} \mathrm{H} \mathrm{O}]$ & 26.0 & 25.3 & 0.458 \\
\hline
\end{tabular}

Table 4: Outcome of lung resection with perioperative fluid greater or less than $1.5 \mathrm{cc} / \mathrm{kg} / \mathrm{hr}$

\begin{tabular}{|c|c|c|c|}
\hline & $\begin{array}{l}\text { Perioperative fluid }<1.5 \mathrm{cc} / \mathrm{kg} / \\
\operatorname{hr}(n=40)\end{array}$ & $\begin{array}{l}\text { Perioperative fluid } \geq 1.5 \mathrm{cc} / \mathrm{kg} / \\
\operatorname{hr}(n=102)\end{array}$ & p-value \\
\hline Duration of hospital stay, mean [days] & 6.2 & 8.9 & 0.069 \\
\hline Duration of ICU stay, mean [days] & 3.1 & 4.7 & 0.276 \\
\hline Duration of chest tube in situ, mean [days] & 4.3 & 6.2 & $0.010^{*}$ \\
\hline $\begin{array}{l}\text { Patients with one or more complications, } \mathrm{n} \\
\qquad(\%)\end{array}$ & $6(15.0)$ & $39(38.2)$ & $0.009^{*}$ \\
\hline Pulmonary complications, $\mathrm{n}(\%)$ & $3(7.5)$ & $24(23.5)$ & $0.032^{*}$ \\
\hline Cardiovascular complications, n (\%) & $2(5.0)$ & $15(14.7)$ & 0.152 \\
\hline Renal complications, n (\%) & $2(5.0)$ & $4(3.9)$ & 0.674 \\
\hline Hemorrhage, n (\%) & $1(2.5)$ & $10(9.8)$ & 0.181 \\
\hline Neurologic complications, $\mathrm{n}(\%)$ & $0(0.0)$ & $2(2.0)$ & 1.000 \\
\hline Reoperation, n (\%) & $0(0.0)$ & $4(3.9)$ & 0.577 \\
\hline Death, n (\%) & $0(0.0)$ & $5(4.9)$ & 0.322 \\
\hline
\end{tabular}

( 4.3 days vs 6.2 days, $\mathrm{p}=0.010$ ). Patients who had one or more complications were also more common in higher perioperative IV fluid group (15.0\% vs $38.2 \%$, p=0.009). The rates of pulmonary complications were significantly higher in the high fluids group (7.5\% vs $23.5 \%, p=0.032$ ). No statistically significant difference was seen in the occurrence of other complications.

\section{Discussion}

Surgical resection of the lung has been a vital part of the treatment for medically suitable patients with early stage NSCLC. Among those resections, lobectomy and bilobectomy are the most commonly performed procedures, with previously published 30 day mortality of $2.6 \%$ [1]. Cardiopulmonary complications, 
especially ALI and ARDS, are the leading cause of postoperative mortality. After Zeldin et al. [5] described postoperative pulmonary edema with increased volume of perioperative IV fluid as a possible risk factor; many began to employ restrictive perioperative fluid management for lung resection. Some have suggested that increase in intra- and postoperative fluid administration is associated with postoperative ALI and ARDS [6-8] while others argue against this [9]. Although many studies have been conducted to elucidate this issue, the definition of liberal and restrictive fluid is vague, and optimal amount of perioperative IV fluid is unclear.

Arslantas et al.[10] reviewed 139 patients who underwent segmentectomy, lobectomy and pneumonectomy and concluded that the intraoperative IV fluid exceeding $6 \mathrm{cc} / \mathrm{kg} / \mathrm{hr}$ is associated with higher risk of pulmonary complications, with IV fluid more than $8 \mathrm{cc} / \mathrm{kg} / \mathrm{hr}$ having a particularly high rate of complications. Interestingly, in our study, intraoperative IV fluid less than $7 \mathrm{cc} / \mathrm{kg} / \mathrm{hr}$ showed no benefit regarding the rate of complications or hospital and ICU stay compare to the group receiving intraoperative IV fluid more than $7 \mathrm{cc} / \mathrm{kg} / \mathrm{hr}$ and less than $10 \mathrm{cc} / \mathrm{kg} / \mathrm{hr}$. In the group receiving more than $10 \mathrm{cc} /$ $\mathrm{kg} / \mathrm{hr}$ intraoperatively, we found a higher rate of one or more complication as well as re-operation. Two of three patients in this group who underwent reoperation were due to hemorrhage and one was secondary to bronchopleural fistula and empyema. Although not statistically significant, there was a trend toward higher rates of hemorrhage in this group compare to the other groups receiving lower intraoperative fluids $(p=0.063)$. Young et al.[11] reported reoperation rate of $1 \%$, with the most common cause as hemorrhage in $73 \%$ followed by bronchopleural fistula in $11 \%$. The most common source of hemorrhage was the bronchial artery. Our study outcomes were in agreement with this finding. Although direct correlation is unclear, tissue edema secondary to excessive IV fluid may compromised the vascular staple line and interrupted hemostasis. Pulmonary complication was also slightly more common in the group receiving liberal intraoperative IV fluid in our study; however this did not reach statistical significance.

Acute renal injury was more commonly observed in the group receiving intraoperative fluid less than $7 \mathrm{cc} / \mathrm{kg} / \mathrm{hr}$. Previous reports have suggested that longer operation times correlate with acute renal injury [12-13]. The duration of operation was statistically longer in patients receiving less IV fluid in our study, and this may be a confounding factor. The patients in our study who developed AKI had a return of their renal function to baseline with medical management without the need for hemodialysis. Furthermore, we observed no additional benefits of restricting intraoperative fluids to less than $7 \mathrm{cc} / \mathrm{kg} / \mathrm{hr}$, which suggest that a more typical rate of $7-10 \mathrm{cc} / \mathrm{kg} / \mathrm{hr}$ may be ideal for intraoperative fluid managements in patient undergoing lobectomy or bilobectomy for NSCLC.

Patients with one or more complications, and pulmonary complications specifically, were more common in the group that received high perioperative IV fluid. Interestingly, duration of the hospital and ICU stay was not affected by the amount of intraoperative or perioperative fluid. Although there are several studies suggesting that the higher amount of perioperative fluids are associated with more pulmonary complications, $[6,14,15]$ it is challenging to determine if the complication is due to the IV fluid administration or if increased IV fluids are subsequently given to the patients who had a complication. Our study did not include oral intake in the perioperative fluids, which also limit the ability to accurately measure perioperative fluids.

In our study, male gender, higher BMI and longer operation were associated with smaller amount of intraoperative IV fluid. This suggests that patients were given a similar amount of fluid without consideration of individual weight or length of the surgery. Both surgeons and anesthesiologists must be cautious about this fact to avoid excessive intraoperative IV fluid and potentially elevate the risk of complications.

Our study is limited by its retrospective nature. Since the groups weren't designated prospectively, it is unclear if there were patient or provider characteristics that influenced fluid management that may have created bias in the data. Furthermore, this study did not look at the use of vasopressors as an adjunct to fluid management. It has been proposed that lowdose vasopressors could potentially help to reduce perioperative fluid requirements and resulting complications, but there is no clear data on the relative outcomes between these strategies [14]

\section{Conclusion}

In our study, we showed that administering high amount of intraoperative and perioperative IV fluid have adverse effects on postoperative complications. Conversely, limiting intraoperative IV fluid ( $<7 \mathrm{cc} / \mathrm{kg} / \mathrm{hr}$ ) has no beneficial effects on outcomes. We propose the optimal amount of intraoperative and perioperative IV fluid administered should be in between these two extremes. A larger prospective randomized multi-center study could be beneficial to compare the outcomes of fluid management with and without low-dose vasopressors to determine if this strategy could reduce the complications found in this study.

\section{Acknowledgements}

\section{Author Contributions}

Megumi Asai and Thai Vu contributed substantially to the study design, data analysis and interpretation, and the writing of the manuscript.

Andres Samayoa had full access to all of the data in the study and takes responsibility for the integrity of the data and the accuracy of the data analysis.

Caitlin Hodge and Ho Pak contributed substantially to the data collection and the writing of the manuscript.

\section{References}

1. Rosen JE, Hancock JG, Kim AW, Detterbeck FC, Boffa DJ. Predictors of mortality after surgical management of lung cancer in the National Cancer Database. Ann Thorac Surg. 2014;98(6):1953-1960. doi: 10.1016/j.athoracsur.2014.07.007

2. Ziarnik E, Grogan EL. Post-lobectomy Early Complications. Thorac Surg Clin. 2015;25(3):355-364. doi: 10.1016/j.thorsurg.2015.04.003

3. Allen MS, Darling GE, Pechet TT, Mitchell JD, Herndon JE 2nd, Landreneau RJ, et al. Morbidity and mortality of major pulmonary resections in patients with early-stage lung cancer: initial results of 
the randomized, prospective ACOSOG Z0030 trial. Ann Thorac Surg. 2006;81(3):1013-1019.

4. Bernard GR, Artigas A, Brigham KL, Carlet J, Falke K, Hudson L, et al. The American-European Consensus Conference on ARDS. Definitions, mechanisms, relevant outcomes, and clinical trial coordination. Am J Respir Crit Care Med. 1994;149(3 Pt 1):818-824.

5. Zeldin RA, Normandin D, Landtwing D, Peters RM. Postpneumonectomy pulmonary edema. J Thorac Cardiovasc Surg. 1984;87(3):359-365.

6. Licker M, de Perrot M, Spiliopoulos A, Robert J, Diaper J, Chevalley $\mathrm{C}$, et al. Risk factors for acute lung injury after thoracic surgery for lung cancer. Anesth Analg. 2003;97(6):1558-1565.

7. Blank RS, Hucklenbruch C, Gurka KK, Scalzo DC, Wang XQ, Jones DR, et al. Intraoperative factors and the risk of respiratory complications after pneumonectomy. Ann Thorac Surg. 2011;92(4):1188-1194. doi: 10.1016/j.athoracsur.2011.06.022

8. Licker M, Diaper J, Villiger Y, Spiliopoulos A, Licker V, Robert J, et al. Impact of intraoperative lung-protective interventions in patients undergoing lung cancer surgery. Crit Care. 2009;13(2):R41. doi: $10.1186 /$ cc7762

9. Fernández-Pérez ER, Keegan MT, Brown DR, Hubmayr RD, Gajic O. Intraoperative tidal volume as a risk factor for respiratory failure after pneumonectomy. Anesthesiology. 2006;105(1):14-18.
10.Arslantas MK, Kara HV, Tuncer BB, Yildizeli B, Yuksel M, Bostanci $\mathrm{K}$, et al. Effect of the amount of intraoperative fluid administration on postoperative pulmonary complications following anatomic lung resections. J Thorac Cardiovasc Surg. 2015;149(1):314-320, 321.e1. doi: 10.1016/j.jtcvs.2014.08.071

11. Yang Y, Gao W, Zhao H, Yang Y, Shi J, Sun Y, Hu D. Risk factors and consequences of perioperative reoperation in patients undergoing pulmonary resection surgery. Surgery. 2016;159(2):591-601. doi: 10.1016/j.surg.2015.07.030

12.Licker M, Cartier V, Robert J, Diaper J, Villiger Y, Tschopp JM, et al Risk factors of acute kidney injury according to RIFLE criteria after lung cancer surgery. Ann Thorac Surg. 2011;91(3):844-850. doi: 10.1016/j.athoracsur.2010.10.037

13.Ishikawa S, Griesdale DE, Lohser J. Acute kidney injury after lung resection surgery: incidence and perioperative risk factors. Anesth Analg. 2012;114(6):1256-1262. doi: 10.1213/ ANE.0b013e $31824 \mathrm{e} 2 \mathrm{~d} 20$

14. Evans RG, Naidu B. Does a conservative fluid management strategy in the perioperative management of lung resection patients reduce the risk of acute lung injury? Interact Cardiovasc Thorac Surg. 2012;15(3):498-504. doi: 10.1093/icvts/ivs175

15.Slinger PD. Perioperative fluid management for thoracic surgery: the puzzle of postpneumonectomy pulmonary edema. J Cardiothorac Vasc Anesth. 1995;9(4):442-451. 